\title{
A importância da coleta de material peniano do suspeito em casos de crimes sexuais: um relato de caso
}

\author{
Rocha, TCL'; Torres, JCN²; Sobreira, ACM²; Brasil, SMV; Cavalcante, IA²; \\ Alencar, $\mathrm{VHM}^{3}$
}

\begin{abstract}
Rocha, TCL; Torres, JCN; Sobreira, ACM; Brasil, SMV; Cavalcante, IA; Alencar, VHM... A importância da coleta de material peniano do suspeito em casos de crimes sexuais: Um relato de caso. Saúde, Ética \& Justiça. 2013;18(Ed. Especial):45-9.
\end{abstract}

RESUMO: A violência sexual é um dos mais ultrajantes tipos de violação dos direitos humanos, expondo a vítima a conseqüências físicas e psicológicas. Avanços nas tecnologias de DNA surtiram um enorme impacto no campo da ciência forense, proporcionando à justiça uma poderosa ferramenta nas investigações de crimes sexuais. No presente trabalho abordamos um caso de estupro perpetrado contra um menor, 11 anos, sexo masculino, autista. Foram coletados swabs oral e anal da vitima e no suspeito coletou-se swabs oral e peniano, visando a análise de DNA. O material coletado foi encaminhado ao Núcleo de Perícias em DNA Forense da (PEFOCE), onde se realizou a extração de DNA por técnicas específicas para cada tipo de amostra. As amostras de DNA foram submetidas à amplificação pelo método da Reação em Cadeia da Polimerase (PCR), utilizando sistemas AmpFSTR®NGM e AmpFSTR囚Yfiler da Applied Biosystems, e Power Plex 16 HS da Promega Corporation. Os produtos de amplificação foram objeto de corrida eletroforética em capilar no aparelho ABI PRISM 3130 Genetic Analyzer da Applied Biosystems. No material anal da vítima foi detectado apenas o seu perfil, não sendo detectado perfil de mistura. Na amostra do swab peniano do acusado, foi constatada presença de perfil genético proveniente de mais de uma pessoa do sexo masculino. Neste perfil de mistura observou-se a presença de todos os alelos da vítima, resultando em uma análise estatística que vincula a vítima ao suposto agressor. O caso abordado demonstra a importância da coleta do material peniano nos casos de crimes sexuais, mesmo quando não há evidências de prática do coito anal e/ou vaginal.

PALAVRAS-CHAVE: Genética forense; Análise de DNA; Crime sexual; Swab peniano.

\footnotetext{
1. Perito Criminal Adjunto da Coordenadoria de Análises Laboratoriais Forenses, Perícia Forense do Estado do Ceará - (PEFOCE), Ceará, - CE.

2. Perito Legista da Coordenadoria de Análises Laboratoriais Forenses, Perícia Forense do Estado do Ceará (PEFOCE), Ceará, - CE.

3. Perito Médico-Legista da Coordenadoria de Medicina Legal, Perícia Forense do Estado do Ceará (PEFOCE), Ceará, - CE.

Endereço para correspondência: E-mail : testinalr@ hotmail.com
} 


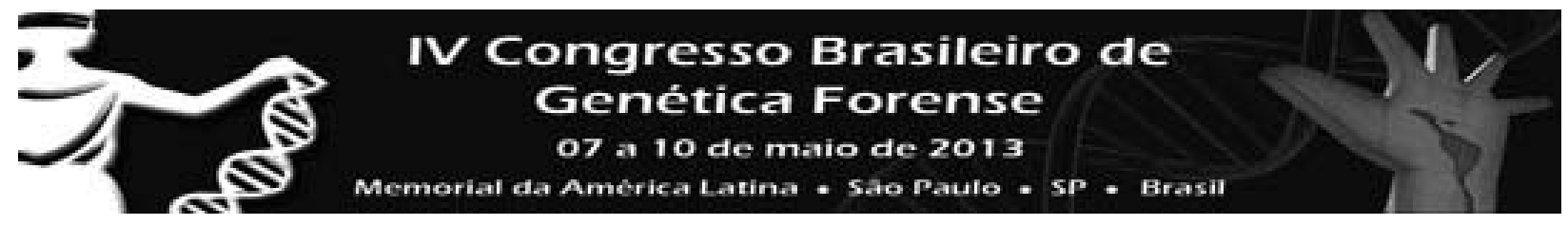

\section{Introdução}

$\mathrm{R}$ econhecida como um fenômeno complexo, a violência pode ser compreendida a partir de diferentes perspectivas e afeta a sociedade como um todo, representando um grave problema de saúde pública ${ }^{1}$. A violência sexual, atinge todas as faixas etárias, classes sociais e ambos os sexos, especialmente crianças, adolescentes e mulheres jovens ${ }^{2}$.

Segundo o Fundo das Nações Unidas para a Infância (UNICEF), por ano cerca de um milhão de crianças em todo o mundo são vitimizadas sexualmente ${ }^{3}$. No Brasil não há dados globais sobre o fenômeno, mas estima-se que menos de $10 \%$ dos casos cheguem às delegacias 4 . Segundo dados da Secretaria de Segurança Pública do Estado do Ceará no ano de 2012 foram realizadas 1061 perícias em vítimas de crimes sexuais na Perícia Forense do Estado do Ceará - (PEFOCE) ${ }^{5}$.

O crime de estupro está previsto no Código Penal Brasileiro nos artigos 213, 217 e 226 com penas que variam de reclusão de 6 a 10 anos, podendo ser aumentadas para até 12 anos se a vítima for menor de 14 anos ou incapaz, e se resultar em morte podem chegar a 30 anos $^{6}$. A Lei 12.015 de 2009 que entrou em vigor em 07 de agosto de 2009 conferiu nova redação ao art. 213 do Código Penal e revogou expressamente o art. 214 do mesmo diploma legal 7 . Por esse novo disciplinamento, a figura típica do estupro passou a ser: "Constranger alguém, mediante violência ou grave ameaça, a ter conjunção carnal ou a praticar ou permitir que com ele se pratique outro ato libidinoso" (Art. 213 do Código Penal Brasileiro). Portanto, passa a ser tipificado como estupro tanto a conjunção carnal, quanto os atos libidinosos diversos daquela ${ }^{7}$. Vê-se que o tipo não distingue o gênero da vítima, motivo pelo qual, desde então, o homem também pode vir a ser vítima desse crime $^{8}$.

Os avanços nas tecnologias de DNA surtiram um enorme impacto no campo da ciência forense, apresentando uma grande sensibilidade e um alto poder de discriminação, proporcionando à justiça uma poderosa ferramenta nas investigações de crimes sexuais?

Quando da análise de material extraído de swab vaginal, anal e/ou swab peniano, em função da natureza do evento sexo-relacionado, podem estar presentes além de espermatozóides, outros tipos de células, frequentemente células epiteliais de vítima e/ou suspeito ${ }^{10}$.
O presente trabalho tem como objetivo apresentar o relato de um caso de crime sexual perpetrado contra um menor, sexo masculino, portador de deficiência mental, onde a coleta do material peniano do suspeito para análise de DNA foi determinante no sucesso da resolução do caso.

\section{Relato do Caso}

A mãe de uma criança de 11 anos, sexo masculino, diagnosticado como autista, fez uma denúncia, pois desconfiava que seu filho havia sido vítima de violência sexual, tendo como autor um vizinho. A vítima e o suspeito foram conduzidos à Perícia Forense do Estado do Ceará, pelas autoridades judiciais.

Foi procedido o exame médico legal e em seguida foram coletados swab oral e anal da vítima. A polícia também encaminhou o acusado para realizar coleta de material genético para investigação do caso, sendo coletados um swab oral e um swab peniano (glande e prepúcio).

De acordo com os achados do exame médico não foram detectadas lesões compatíveis com coito anal ou sinais de violência na criança, portanto os achados laboratoriais (análise de DNA) passariam a ser a principal fonte de evidências do delito. Os resultados das análises laboratoriais não detectaram a presença de esperma humano na amostra colhida da região anal da vítima, no entanto foi detectado DNA da vítima no swab peniano do suspeito, fato este que sob o prisma da nova lei pode caracterizar crime de estupro.

\section{Materiais e Métodos}

\section{Análise para detecção de esperma humano}

Foi realizadaa pesquisa de espermatozóides, por técnica de microscopia óptica e exame presuntivo de esperma humano através da detecção de PSA (proteína prostática específica), utilizando-se técnica de imunocromatografia.

\section{Extração de DNA}

As amostras-referência (swab oral da vítima e do acusado) foram submetidas ao método de extração com a resina Chelex® 100 e as questionadas (swab retal da vítima e swab peniano do acusado) ao método de extração orgânica, para obtenção do DNA genômico. 


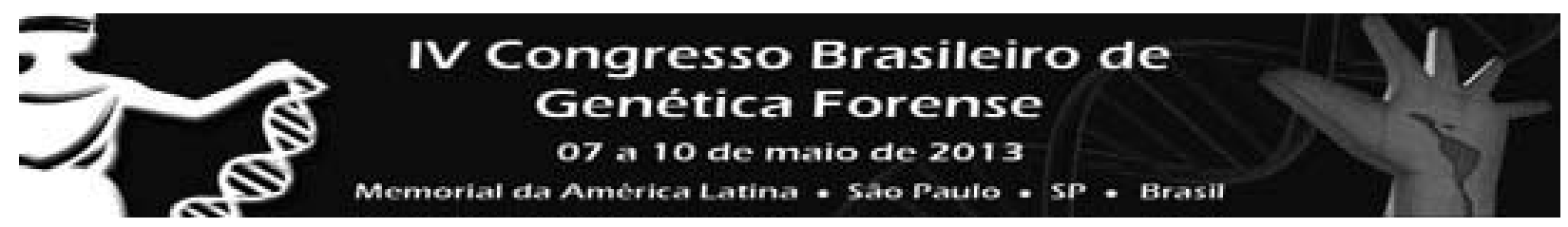

\section{Amplificação de DNA}

As amostras de DNA foram submetidas à amplificação pelo método de (PCR), utilizando os sistemas AmpFSTR® NGM, AmpFSTR®Yfiler da Applied Biosystems e Power Plex 16 HS da Promega Corporation totalizando 23 (vinte e três) loci gênicos e 16 (dezesseis) haplotípicos.

\section{Revelação dos perfis alélicos}

Os produtos de amplificação obtidos com os sistemas foram objeto de corrida eletroforética em capilar no aparelho ABI PRISM 3130 Genetic Analyzer da Applied Biosystems.

\section{Análise estatística}

A análise estatística foi realizada utilizando-se o programa DNA MIX-versão $3.2^{11}$.

\section{Resultados e Discussão}

\section{Análise presuntiva de Esperma Humano}

Não foi detectado esperma humano na amostra do conteúdo anal da vítima, levando a fortes indícios de que não houve coito anal.

\section{Análise de STRs autossômicos}

$\mathrm{Na}$ amostra obtida do swab anal coletado da vítima foi constatada presença de material genético proveniente somente da vítima.

De acordo com Farmen e col. ${ }^{12}$, em 2012, o DNA feminino pode ser extraído de amostras de swab peniano de suspeitos de praticar estupro até 24 horas após a relação sexual, mostrando que esse tipo de amostra pode ser bastante informativo em casos de crimes sexuais. Outro estudo Kaarstad et al ${ }^{13}$, em 2007, observou que o intervalo de tempo entre o estupro e a coleta do material peniano, deve ser em média 7 horas, e quanto menor o tempo transcorrido melhor a identificação completa dos marcadores autossômicos da vítima, demonstrando que o tempo entre a ocorrência do estupro e a realização da perícia é determinante para o sucesso da identificação dos alelos ${ }^{13}$. Neste caso foi observado que na amostra obtida do swab peniano, coletado do acusado, foi constatado a presença do perfil genético completo do acusado e da vítima, embora o inquérito não tenha sido informativo sobre o transcurso de tempo entre o ato sexual e a coleta do material (Tabela 1).

TABELA 1. Perfil genético obtido das amostras em 18 (dezoito) loci gênicos

\begin{tabular}{|c|c|c|c|c|}
\hline locus gênico & $\begin{array}{l}\text { Swab anal } \\
\text { vítima }\end{array}$ & $\begin{array}{l}\text { Swab peniano } \\
\text { acusado }\end{array}$ & $\begin{array}{c}\text { Amostra-referência } \\
\text { vítima }\end{array}$ & $\begin{array}{c}\text { Amostra-referência } \\
\text { acusado }\end{array}$ \\
\hline D8S1179 & $13-16$ & $12-13-14-16$ & $13-16$ & $12-14$ \\
\hline D21S11 & $28-29$ & $28-29-30$ & $28-29$ & $29-30$ \\
\hline D7S820 & $9-11$ & $9-11$ & $9-11$ & 9 \\
\hline CSF1PO & $11-13$ & $11-13$ & $11-13$ & 11 \\
\hline D3S1358 & $16-17$ & $16-17$ & $16-17$ & $16-17$ \\
\hline THO1 & $8-10$ & $6-8-9.3-10$ & $8-10$ & $6-9.3$ \\
\hline D13S317 & $9-11$ & $9-11-13$ & $9-11$ & $9-13$ \\
\hline D16S539 & $11-14$ & $11-12-14$ & $11-14$ & $11-12$ \\
\hline D19S433 & $12.2-15$ & $12.2-14-15$ & $12.2-15$ & $14-15$ \\
\hline VWA & 18 & $16-18-19$ & 18 & $16-19$ \\
\hline TPOX & 8-11 & $8-11$ & 8-11 & 8-11 \\
\hline D18S51 & 15 & $15-16$ & 15 & $15-16$ \\
\hline FGA & $19-20$ & $19-20-23$ & $19-20$ & $20-23$ \\
\hline Penta - E & $9-16$ & $9-14-16$ & $9-16$ & $9-14$ \\
\hline Penta - D & $11-12$ & $11-12$ & $11-12$ & 11 \\
\hline D10S1248 & 15 & $12-15$ & 15 & 12 \\
\hline D12S391 & 19.1 & $17-19.1-22$ & 19.1 & $17-22$ \\
\hline Amelogenina & $X-Y$ & $X-Y$ & $X-Y$ & $X-Y$ \\
\hline
\end{tabular}

${ }^{\star}$ Os alelos de cada locus gênico estão representados pelos números dentro das colunas. 


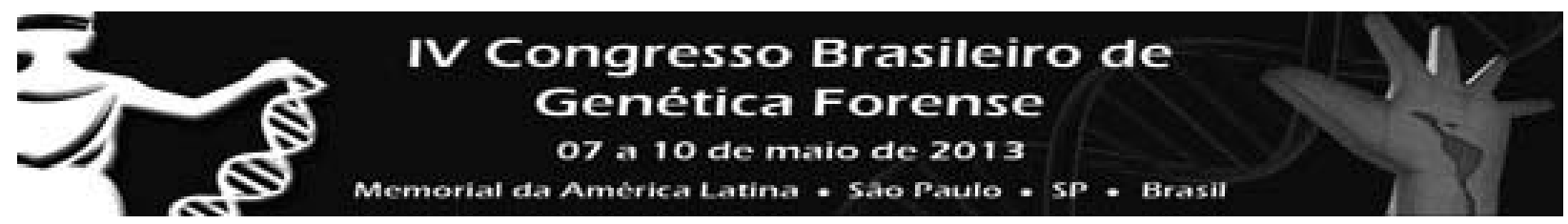

Para determinar a quem pertence o segundo contribuinte da referida amostra foram estabelecidas duas hipóteses ( $\mathrm{H} 1$ e $\mathrm{H} 2)$ :

$\mathrm{H} 1$ - As pessoas que contribuíram com material genético para produção da referida amostra questionada foram o acusado e a vítima;

$\mathrm{H} 2$ - As pessoas que contribuíram com material genético para produção da referida amostra questionada foram o suspeito e uma terceira pessoa desconhecida.

Para testar as hipóteses, foram identificados todos os possíveis genótipos do segundo contribuinte da amostra em questão. Procedendo a comparação desses genótipos com o perfil da vítima, foi verificada sua inclusão como um dos contribuintes, junto com o acusado, para produção desta amostra.

De acordo com os cálculos estatísticos, confrontadas as duas hipóteses acima mencionadas, utilizando-se o programa DNA MIXversão 3.2, verificou-se que a possibilidade da vítima ter contribuído, junto com o acusado, para a produção da mistura de material genético presente na amostra extraída do swab peniano é 216,5 quintilhões de vezes maior que a possibilidade de uma terceira pessoa ter contribuído, junto com o acusado, para a produção desta mistura.

\section{Análise de Y-STRs}

Utilizando-se os marcadores para o cromossomo $\mathrm{Y}$, específicos para indivíduos do sexo masculino, na amostra retirada dos swabs anais coletados da vítima foi observado um único perfil haplotípico do cromossomo $\mathrm{Y}$ coincidente com o obtido do material genético proveniente da referida vítima.

Na amostra retirada do swab peniano coletado do acusado, foi encontrado um perfil haplotípico parcial de mistura de mais de um indivíduo do sexo masculino. Os alelos da vítima estavam presentes na maioria dos loci em que houve amplificação.

\section{Conclusão}

O caso abordado demonstra a importância da coleta do material peniano nos suspeitos de crimes sexuais, pois no caso relatado o suspeito teve a sua participação comprovada no delito, através de análise dos perfis genéticos, mesmo não tendo evidências de coito anal. Vale ressaltar que de acordo com a Lei 12.015 de 2009 o crime de atentado violento ao pudor foi fundido ao de estupro, levando com isso a uma profunda mudança no Código Penal Brasileiro. Baseado nesta mudança torna-se de extrema importância a identificação do material genético da vítima no órgão genital do agressor, vinculando a vítima ao acusado e desta maneira podendo se caracterizar o estupro. Acreditamos que com a padronização desse tipo de coleta nos centros de perícias de todo o Brasil, teremos uma ferramenta científica a mais para desvendar esse tipo de crime, cada vez mais frequente em nossa sociedade.

Rocha, TCL; Torres, JCN; Sobreira, ACM; Brasil, SMV; Cavalcante, IA; Alencar, VHM. The importance of sample suspect's penile material in sexual assault case: a case report. Saúde, Ética \& Justiça. 2013;18(Ed. Especial):45-9.

ABSTRACT: Sexual violence is one of the most offensive acts of violation of human rights, exposing the victim to physical and psychological consequences. Advances in DNA technology have produced a huge impact on the field of forensic science, providing a strong tool to the justice in the investigation of sexual crimes. In this paper we discuss a case of rape perpetrated against a minor, 11 year-old male, autistic. We collected oral and anal swabs of the victim and, in the suspect, was collected oral and penile swab, aiming to DNA analysis. The collected material was sent to the Núcleo de Perícias em DNA Forense da (PEFOCE), where was performed the DNA extraction by specific techniques for each type of sample. The DNA samples have been subjected to amplification by the method of Polymerase Chain Reaction (PCR) with the systems I STR ® NGM AmpF and AmpF I STR $®$ Yfiler Applied Biosystems, and Power Plex 16 HS Promega Corporation. The amplicons were analyzed in automatic sequencer ABI PRISM 3130 Genetic Analyzer from Applied Biosystems. In the material of anal victim was detected only his profile, not being detected profile mixing. In penile swab sample of the accused, was found presence of genetic profile from more than one male. In this profile mixing we observed the presence of all alleles of the victim, resulting in a statistical analysis that links the victim to the supposed offender. The case discussed demonstrates the importance of collecting penis material in cases of sexual offenses, it was not even concluded being practiced anal intercourse.

KEYWORDS: Forensic genetics; DNA analysis; Sexual crime; Penile swab. 


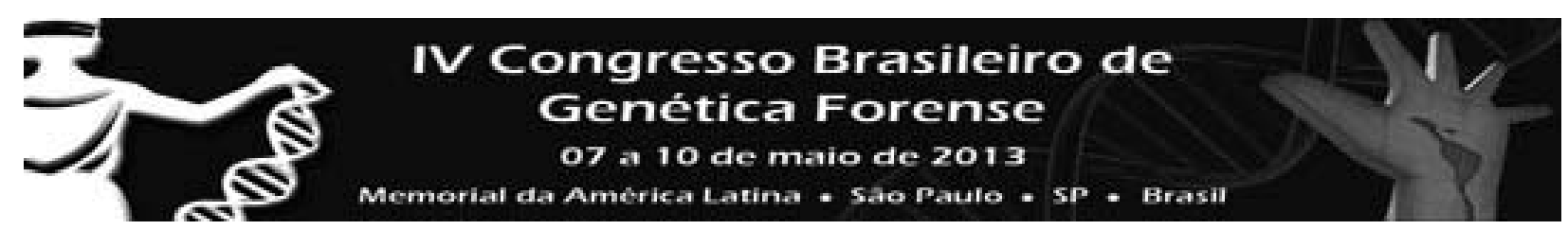

\section{REFERÊNCIAS}

1. Ribeiro AM, Ferriani MGC, Reis JN. Violência sexual contra crianças e adolescentes: características relativas à vitimização nas relações familiares. Cad Saúde Pública. 2004;20:456-64.

2. Lopes IMRS, Gomes KRO, Silva, BB, Deu, MCB., Galvão ERCGN, Borba D C. Caracterização da violência Sexual em mulheres atendidas no Projeto Maria-Maria em Teresina - PI. Rev Bras Ginecol Obst. 2004;26:111-6.

3. Inoue SRV, Ristum M. Violência sexual: caracterização e análise de casos revelados na escola. Estudos Psicol. 2008; 25:11-21.

4. Aded NLO, Dalcin BLGS, Moraes TM, Cavalcanti MT. Abuso sexual em crianças e adolescentes: revisão de 100 anos de literatura. Rev Psiquiatr Clín. 2006;33:204-13.

5. Brasil. Estatística, Perícia Forense do Estado do Ceará - (PEFOCE), Secretaria de Segurança Pública e Defesa Social do Estado do Ceará, 2012.

6. Brasil. Código Penal Brasileiro, 7 de Dezembro de 1940. Disponível em: www.planalto.gov.br
7. Brasil. Lei 12.015 de 07 de agosto 2009. Disponível em: www.planalto.gov.br

8. Prado, Luiz Regis, Curso de direito penal brasileiro. Parte geral. 5a ed. rev. São Paulo: Revista dos Tribunais; 2005. v.1, p. 201-2.

9. Benecke M. DNA typing in forensic medicine and in criminal investigations: a current survey. Naturwissenschaften. 1997;84:181-8.

10. Teixeira WRG. A importância do Swab na perícia de estupro. Rev IMESC. 1998;1.

11. Curran JM, Triggs CM, Buckleton J, Weir BS. Interpreting DNA mixtures in structured populations. J Forensic Sci. 1999;44(5);987-95

12. Farmen RK, Haukeli I, Ruoff P, Frøyland ES. Assessing the presence of female DNA on post-coital penile swabs: Relevance to the investigation of sexual assault. J Forensic Leg Med. 2012;19(7):386-9.

13. Kaarstad K, Rohde M, Larsen J, Eriksen B, Thomsen $\mathrm{JL}$. The detection of female DNA from the penis in sexual assault cases. J Forensic Leg Med. 2007;14:159-60. 